\title{
EDUKASI TENTANG 1000 HARI PERTAMA KEHIDUPAN TERHADAP PENGETAHUAN IBU HAMIL DI WILAYAH KERJA PUSKESMAS TAMALATE MAKASSAR
}

\section{Education of the Importance of the First 1000 Days of Life On Knowledge of Pregnant Women in the Working Area of Tamalate Puskesmas Makassar City}

\author{
Zulaeha A Amdadi, Fitriati Sabur, Afriani \\ Jurusan Kebidanan Poltekkes Kemenkes Makassar \\ afriani@poltekkes-mks.ac.id \\ Hp. 081342412307
}

\begin{abstract}
ABSTRAK
Pemenuhan gizi yang optimal selama masa 1000 hari pertumbuhan, diperlukan upaya perbaikan gizi sejak ibu hamil, bayi, dan balita, sehingga melahirkan anak yang sehat. Nutrisi yang tepat selama periode 1000 hari ini dapat memberi dampak besar pada kemampuan seorang anak untuk tumbuh, belajar, dan bangkit dari kemiskinan. Dalam skala besar dan jangka panjang, hal ini juga berkontribusi pada kesehatan masyarakat, stabilitas dan kemakmuran suatu Negara. Para ilmuwan, ekonom dan pakar kesehatan sepakat bahwa perbaikan gizi selama periode 1000 hari awal kehidupan adalah salah satu investasi terbaik yang dapat kita lakukan untuk mencapai kemajuan yang abadi dalam kesehatan global dan pembangunan. Salah satu upaya yang dilakukan adalah dengan meningkatkan pengetahuan ibu hamil tentang pentingnya 1000 hari pertama kehidupan di wilayah kerja Puskesmas Tamalate Makassar. Tujuan Penelitian ini yaitu untuk mengetahui Pengaruh edukasi tentang pentingnya 1000 hari pertama kehidupan pada ibu hamil di wilayah kerja Puskesmas Tamalate Kota Makassar. Penelitian ini menggunakan quasi experimen designs dengan rancangan one group pretest-postest. Populasi dalam penelitian ini adalah semua ibu hamil di Wilayah kerja Puskesmas Tamalate Makassar sebanyak 351 orang. Teknik pengambilan sampel adalah purposive sampling dengan jumlah sampel sebanyak 89 orang. Analisis data hasil penelitian dengan analisis univariat, bivariat dengan menggunakan uji McNemar. Hasil penelitian menunjukkan bahwa ada pengaruh signifikan pelaksanaan edukasi pada ibu hamil terhadap peningkatan pengetahuan ibu hamil tentang 1000 HPK dengan nilai $p=0,00$. Disarankan kepada institusi/fasilitas kesehatan untuk lebih meningkatkan edukasi pada ibu hamil terhadap pentingnya $1000 \mathrm{HPK}$.
\end{abstract}

Kata kunci: Edukasi, 1000 hari pertama kehidupan, hamil, pengetahuan

\section{ABSTRACT}

Fulfillment of optimal nutrition during the 1000 days of growth requires efforts to improve nutrition since pregnant women, babies and toddlers, so as to give birth to healthy children. Proper nutrition during this 1000 day period can have a profound impact on a child's ability to grow, learn and rise out of poverty. On a large scale and long term, it also contributes to the public health, stability and prosperity of a country. Scientists, economists and health experts agree that improving nutrition during the first 1000 days of life is one of the best investments we can make to achieve lasting progress in global health and development. One of the efforts made is to increase the knowledge of pregnant women about the importance of the first 1000 days of life in the working area of Puskesmas Tamalate Makassar. The purpose of this study was to determine the effect of education on the importance of the first 1000 days of life in pregnant women in the working area of Puskesmas Tamalate, Makassar City. This study used a quasi experimental design with a one group pretest-postest design. The population in this study were all pregnant women in the working area of Puskesmas Tamalate Makassar as many as 351 people. The sampling technique was purposive sampling with a sample size of 89 people. Analysis of research data using univariate, bivariate analysis using McNemar. The results showed that there was a significant effect of the implementation of education on pregnant women on increasing the knowledge of pregnant women about $1000 \mathrm{HPK}$ with a value of $p=0.00$. It is recommended for health institutions / facilities to further improve education for pregnant women on the importance of $1000 \mathrm{HPK}$.

Keywords : Education, in 1000 the first life, Mrs. Hamil, increase knowledge.

\section{PENDAHULUAN}

Berdasarkan hasil Riset Kesehatan Dasar (Riskesdas tahun 2018), persentase BBLR di Indonesia sebesar 6,2 persen, anak balita pendek sebesar 22,7 persen, anak balita kurus sebesar 15,9 persen, anak balita gizi kurang sebesar 17,9 persen. Sepertiga anak Indonesia usia dibawah lima tahun mempunyai status gizi stunting atau pendek, lebih dari seperlima anak sudah mengalami stunting pada usia 0-5 bulan, mencapai puncaknya pada usia antara 2-3 tahun, yaitu lebih dari $40 \%$. Prevalensi stunting pada balita dari kelompok masyarakat termiskin lebih tinggi dibandingkan kelompok masyarakat terkaya, tetapi prevalensi pada kelompok terkaya juga sangat tinggi yaitu $30 \%$. Hal ini mengindikasikan bahwa sebagian besar masyarakat Indonesia pernah mengalami kekurangan gizi kronis dan berulang, yang 
dimulai pada usia sangat dini (Riskesdas, 2018).

Dampak buruk yang dapat ditimbulkan oleh masalah gizi tersebut diatas, dalam jangka pendek adalah terganggunya perkembangan otak, kecerdasan, gangguan pertumbuhan fisik, dan gangguan metabolisme dalam tubuh. Sementara dalam jangka panjang, akan mengakibatkan menurunnya kemampuan kognitif dan prestasi belajar, menurunnya kekebalan tubuh sehingga mudah sakit, dan risiko tinggi untuk munculnya penyakit diabetes, kegemukan, penyakit jantung dan pembuluh darah, kanker, stroke, dan disabilitas pada usia tua. Keseluruhan hal tersebut akan menurunkan kualitas sumber daya manusia Indonesia, produktivitas, dan daya saing bangsa.

Di samping masalah kematian bayi yang didominasi kematian neonatal, angka kematian ibu (AKI) di Indonesia masih tertinggi di antara Negara ASEAN dan tren penurunannya sangat lambat. Survey Demografi dan Kesehatan Indonesia (SDKI) 2012 memberikan hasil yang mengejutkan, angka kematian ibu (AKI) meningkat 359 per 100 ribu kelahiran hidup. Rata-rata kematian ini jauh melonjak dibanding hasil SDKI 2007 yang mencapai 228 per 100 ribu. Dalam hal ini, meningkatnya $\mathrm{AKI}$ ini menjadi tantangan besar bagi bangsa Indonesia.

Fakta-fakta ilmiah sudah sangat jelas diuraikan bahwa kelalaian atau kelengahan memperbaiki gizi pada awal kehidupan, yakni pemenuhan asupan gizi (makro dan mikro) secara seimbang, yang diperoleh dari saat tumbuh dalam rahim ibunya, menyusui (ASI) eksklusif sampai 6 bulan, dan diteruskan dengan ASI dan makanan peralihan ASI (MP-ASI), akan menentukan masa depan anak di kemudian hari. Pertumbuhan bayi yang sehat akan menjadikannya anak yang sehat dan produktif, dan terus berkembang menjadi orang dewasa yang mampu membangun keluarga yang juga sehat dan produktif. Jika ini terjadi, rantai kemiskinan berhasil diputus, dan diharapkan keluarga yang sehat akan tumbuh.

$$
\text { Mutiara R (2017) dalam }
$$

penelitiannya hubungan pengetahuan 1000 hari pertama kehidupan dan dukungan keluarga dengan kepatuhan ibu hamil dalam mengonsumsi tablet fe memaparkan bahwa $10,7 \%$ ibu hamil memilki kepatuhan yang tinggi, 33,9\% memiliki kepatuhan sedang dan 55,4\% memiliki kepatuhan yang rendah. Usia ibu, status bekerja, pendidikan, riwayat kehamilan dan usia kehamilan tidak memiliki hubungan dengan kepatuhan konsumsi tablet Fe. Pengetahuan 1000 Hari Pertama Kehidupan $(p=0,000)$ dan dukungan keluarga $(p=0,001)$ memiliki hubungan dengan kepatuhan konsumsi tablet $\mathrm{Fe}$. Kepatuhan yang tinggi dimiliki oleh ibu hamil yang memiliki pengetahuan 1000 hari pertama kehidupan dan dukungan keluarga yang tinggi. Pengetahuan tentang 1000 hari pertama kehidupan pada ibu hamil adalah hal yang penting untuk mempersiapkan kehamilan yang sehat, sehingga informasi mengenai 1000 HPK perlu diberikan. Keluarga juga harus memberikan dukungan yang baik dalam konsumsi tablet $\mathrm{Fe}$.

Shofiyyatunnisaa (2016), dalam penelitiannya yang bertujuan untuk mengkaji perilaku ibu tentang 1000 hari pertama kehidupan dan kaitannya dengan status gizi baduta, menunjukkan adanya hubungan yang signifikan antara sikap dan praktik responden tentang masa perawatan bayi $0-6$ bulan dengan status gizi baduta BB/TB $(p<0.05)$. Ada kecenderungan hubungan antara pengetahuan pada masa kehamilan dengan status gizi BB/TB $(p=0.075 ; \quad r=-0.247)$. Hubungan yang signifikan juga didapatkan antara pengetahuan dengan sikap responden tentang gizi dan 1000 HPK $\quad(p=0.043$; $r=0.279$ ), sedangkan antara pengetahuan dengan praktik responden tentang gizi dan 1000 HPK tidak ada hubungan yang signifikan ( $p=0.758 ; r=0.043$ ), demikian pula antara sikap dengan praktik responden tentang gizi dan 1000 HPK $\quad(p=0.364$; $r=0.127$ ).

Dian Nurlaela (2018), dalam penelitiannya yang bertujuan Untuk mengetahui efektivitas pendidikan kesehatan melalui media KCA tentang 1000 HPK dalam meningkatkan pengetahuan calon pengantin di KUA Kecamatan Jatinangor, menunjukan bahwa penggunaan media KCA efektif dalam meningkatkan pengetahuan catin tentang 1000 HPK, hasil Uji Paired Sample t-test dengan nilai $p=0,000$ yang artinya terdapat perbedaan yang signifikan terhadap peningkatan pengetahuan catin sebelum dan sesudah diberikan pendidikan Kesehatan

Tujuan umum penelitian ini adalah Untuk mengetahui pengaruh edukasi 
pentingnya 1000 hari pertama kehidupan terhadap pengetahuan ibu hamil di wilayah kerja Puskesmas Tamalate Makassar.

\section{METODE PENELITIAN}

Penelitian ini dilaksanakan di RS. Bhayangkara Makassar. Desain penelitian menggunakan desain Pre experiment designs dengan rancangan one group pretest-postest. Populasi dalam penelitian ini adalah semua ibu hamil di Wilayah kerja Puskesmas Tamalate. Sampel penelitian adalah semua ibu hamil di yang memeriksakan kehamilannya di di Puskesmas Tamalate Makassar dengan teknik purposive sampling yang berjumlah 89 orang yang telah memenuhi syarat kriteria inklusi sebagai berikut : ibu hamil yang berdomisili di wilayah kerja Puskesmas Tamalate Kota Makassar, ibu dan janinnya dalam kondisi sehat wal afiat, bersedia menjadi responden dan memiliki waktu luang untuk menerima edukasi tentang 1000 Hari Pertama Kehidupan sedangkan kriteria ekslusi adalah ibu hamil yang sedang sakit / dalam perawatan RS, tidak hadir di Puskesmas Tamalate pada saat penelitian berlangsung.

Sumber data penelitian adalah data primer yang diperoleh langsung dari ibu hamil dengan ini menggunakan kuesioner untuk mengukur pengetahuan ibu hamil tentang pentingnya 1000 hari pertama kehidupan sebelum dan setelah penyuluhan. Teknik analisis data yang digunakan adalah analisis univariat dan analisis bivariat dengan menggunakan uji McNemar.

\section{HASIL DAN PEMBAHASAN}

Penelitian ini dilaksanakan di Puskesmas Tamalate Makassar. Hasil analisis disajikan dalam bentuk tabel yang dilengkapi dengan penjelasan tabel sebagai berikut:

Tabel 1 menunjukkan jumlah responden terbanyak pada umur 20-35 tahun $(74,2 \%)$, usia ini adalah usia reproduksi yang baik untuk masa kehamilan, bersalin dan menyusui. Umur kehamilan terbanyak adalah trimester 2 dan 3 masing-masing (34,8\%). Dari data tingkat pendidikan menunjukkan tingkat pendidikan SMA yang tertinggi yaitu $76,4 \%$ dan paling sedikit adalah di tingkat pendidikan perguruan tinggi (2,2\%). Dari data pekerjaan, mayoritas ibu yang menjadi responden tidak bekerja atau ibu rumah tangga $(56,2 \%)$.

Tabel 2. Menunjukkan bahwa sebanyak 39 (43,8\%) responden dengan pengetahuan baik tentang 1000 HPK dan $50 \quad(56,2 \%)$ responden dengan pengetahuan kurang tentang $1000 \mathrm{HPK}$.

Tabel 3. menunjukkan bahwa sebanyak $84(94,4 \%)$ responden dengan pengetahuan baik tentang $1000 \mathrm{HPK}$ dan 5 $(5,6 \%)$ responden dengan pengetahuan kurang tentang 1000 Hari Pertama Kehidupan.

Hasil analisis pada tabel 4, hasil pretest dengan pengetahuan baik 39 $(43,8 \%)$ dan pengetahuan kurang 50 $(56,2 \%)$. Hasil posttest dengan pengetahuan baik $84 \quad(94,4 \%)$ dan pengetahuan kurang 5 (5,6\%). Hal tersebut menunjukkan adanya peningkatan pengetahuan sebelum dilaksanakan edukasi dan setelah dilaksanakan edukasi pada ibu hamil. Hasil analisis uji McNemar dengan $p$ value sebesar 0.000 , secara statistik menunjukkan ada pengaruh signifikan pelaksanaan edukasi pada ibu hamil tentang $1000 \mathrm{HPK}$.

\section{PEMBAHASAN}

Berdasarkan banyak penelitian, para ahli menyimpulkan bahwa periode 1000 hari adalah periode emas yang dimulai sejak saat konsepsi, pertumbuhan janin dalam rahim, hingga ulang tahun ke 2 kehidupannya,yang akan menentukan kualitas kesehatan pada kehidupan selanjutnya. Bukan hanya kesehatan secara lahiriah lebih dari itu, kesehatan jiwa dan emosi, bahkan kecerdasan/ intelektualnya. Hal ini berarti nutrisi selama periode emas ini sangat menentukan, ibarat kita membangun sebuah rumah yang kokoh dan indah, maka seharusnya bahan yang digunakan harus berkualitas, terencana dan terpantau dengan baik.

Pendidikan adalah elemen kunci dalam keberhasilan kesehatan layanan perawatan, termasuk edukasi optimalisasi nutrisi pada ibu hamil dan pendekatan terbaik adalah edukasi yang melibatkan keluarga sebagai orang terdekat bagi klien. Edukasi berbasis keluarga merupakan salah satu upaya pemberdayaan untuk memperkuat peran keluarga sebagai lingkungan yang paling berpengaruh terhadap status kesehatan anggota keluarga, khususnya pada ibu hamil. Penelitian tentang pengaruh edukasi 
berbasis keluarga telah banyak dilakukan oleh peneliti lain, demikian pula dengan penelitian-penelitian yang menggunakan Theory of Planned Behavior sebagai framework. Namun dalam penelitian ini, peneliti mencoba untuk mengetahui pengaruh edukasi berbasis keluarga terhadap intensi ibu hamil untuk optimalisasi nutrisi pada 1000 Hari Pertama Kehidupan dengan menggunakan metode ceramah, yang mana metode ini cukup baik pada sasaran dengan pendidikan tinggi dan rendah.

Hasil analisis data dengan menggunakan uji McNemar pada tabel 4 , dapat diketahui bahwa $p$ value $0.000<0.05$ yang berarti bahwa ada pengaruh signifikan pelaksanaan edukasi pada ibu hamil terhadap peningkatan pengetahuan ibu hamil tentang 1000 HPK di Wilayah Kerja Puskesmas Tamalate Makassar.

Rosani Naim (2017) mengemukakan bahwa ada perbedaan pengetahuan, sikap dan intensi para siswa Sekolah Dasar di Jambi untuk mencuci tangan menggunakan sabun melalui metode ceramah, demonstrasi dan latihan. Adapun media yang digunakan berupa lembar balik dan modul yang dapat dibaca sewaktuwaktu serta mudah dipahami oleh ibu hamil, suami dan atau anggota keluarga lainnya. Siti (2016) dalam penelitiannya berpendapat bahwa penggunaan media pembelajaran terhadap materi yang diajarkan merupakan faktor yang memengaruhi efektifitas dalam proses pendidikan sebab periode emas tumbuh kembang anak adalah penentu masa depan anak terhadap kondisi kesehatannya, kecerdasan fisik dan mental anak serta daya saing anak sebagai generasi penerus bangsa. Oleh karena itu, intervensi edukasi ini diharapkan dapat meningkatkan niat ibu dan pada akhirnya menjadi perilaku pada ibu hamil dan keluarga terhadap pemenuhan gizi pada 1000 HPK.

Mutiara R (2017) dalam penelitiannya hubungan pengetahuan 1000 hari pertama kehidupan dan dukungan keluarga dengan kepatuhan ibu hamil dalam mengonsumsi tablet fe memaparkan bahwa $10,7 \%$ ibu hamil memilki kepatuhan yang tinggi, 33,9\% memiliki kepatuhan sedang dan $55,4 \%$ memiliki kepatuhan yang rendah. Usia ibu, status bekerja, pendidikan, riwayat kehamilan dan usia kehamilan tidak memiliki hubungan dengan kepatuhan konsumsi tablet Fe. Pengetahuan 1000 Hari Pertama Kehidupan $(p=0,000)$ dan dukungan keluarga $(p=0,001)$ memiliki hubungan dengan kepatuhan konsumsi tablet $\mathrm{Fe}$. Kepatuhan yang tinggi dimiliki oleh ibu hamil yang memiliki pengetahuan 1000 hari pertama kehidupan dan dukungan keluarga yang tinggi. Pengetahuan tentang 1000 hari pertama kehidupan pada ibu hamil adalah hal yang penting untuk mempersiapkan kehamilan yang sehat, sehingga informasi mengenai 1000 HPK perlu diberikan. Keluarga juga harus memberikan dukungan yang baik dalam konsumsi tablet $\mathrm{Fe}$.

Shofiyyatunnisaak (2016), dalam penelitiannya yang bertujuan untuk mengkaji perilaku ibu tentang 1000 hari pertama kehidupan dan kaitannya dengan status gizi baduta, menunjukkan adanya hubungan yang signifikan antara sikap dan praktik responden tentang masa perawatan bayi 0-6 bulan dengan status gizi baduta BB/TB $(p<0.05)$. Ada kecenderungan hubungan antara pengetahuan pada masa kehamilan dengan status gizi BB/TB $(p=0.075 ; \quad r=-0.247)$. Hubungan yang signifikan juga didapatkan antara pengetahuan dengan sikap responden tentang gizi dan 1000 HPK $\quad(p=0.043$; $r=0.279$ ), sedangkan antara pengetahuan dengan praktik responden tentang gizi dan 1000 HPK tidak ada hubungan yang signifikan ( $p=0.758 ; r=0.043$ ), demikian pula antara sikap dengan praktik responden tentang gizi dan 1000 HPK $(p=0.364$; $r=0.127$ ).

Dian Nurlaela (2018), dalam penelitiannya yang bertujuan Untuk mengetahui efektivitas pendidikan kesehatan melalui media KCA tentang 1000 HPK dalam meningkatkan pengetahuan calon pengantin di KUA Kecamatan Jatinangor, menunjukan bahwa penggunaan media KCA efektif dalam meningkatkan pengetahuan catin tentang 1000 HPK, hasil Uji Paired Sample t-test dengan nilai $p=0,000$ yang artinya terdapat perbedaan yang signifikan terhadap peningkatan pengetahuan catin sebelum dan sesudah diberikan pendidikan kesehatan.

Menurut Notoatmojo dalam Ikada (2017) Pengetahuan gizi merupakan pengetahuan tentang peran makanan dan zat gizi, sumber zat gizi pada makanan, makanan yang aman dimakan dan cara mengolah makanan yang baik serta 
bagaimana cara hidup sehat. Pengetahuan gizi memiliki tujuan mendorong terjadinya perubahan perilaku gizi yang positif dan bersifat terus menerus. Semakin tinggi pengetahuan gizi seseorang maka ia akan semakin memperhitungkan jenis dan kualitas makanan yang dipilih untuk dikonsumsi (Sediaoetoma, 2017). Sedangkan menurut Suhardjo (2016) pengetahuan gizi memegang peranan penting dalam penggunaan dan pemilihan bahan makanan yang baik sehingga dapat mencapai keadaan gizi yang seimbang

Para ahli menemukan setidaknya ada 50 jenis zat yang mempengaruhi fungsi otak selama 1000 hari awal kehidupan ini. Kegagalan dalam asupan nutrisi pada periode ini akan mempunyai efek jangka panjang dan sulit, bahkan tidak dapat diubah lagi, seperti kerentanan terhadap penyakit infeksi, kemungkinan menderita penyakit degeneratif (hipertensi, jantung, stroke, diabetes dII), bahkan kanker dan kelainan jiwa. Pemenuhan gizi yang optimal, lingkungan pertumbuhan yang kondusif pada masa janin dan bayi, dan imunisasi selama periode ini akan memberi kesempatan hidup lebih lama, lebih sehat, lebih produktif dengan kualiitas yang lebih baik, serta risiko yang lebih rendah terhadap penyakit degeneratif.

Pentingnya periode 1000 hari awal kehidupan pada perkembangan otak mulai fase janin dan bayi hingga 2 tahun, perannya dalam pembentukan otak sosial, belajar keterampilan fisik, belajar berbicara, belajar tentang benar dan salah, perannya pada kualitas kesehatan jangka panjang hingga pada skala yang lebih luas, berpengaruh secara sosial ekonomi pada kemiskinan/kemakmuran. Untuk pemenuhan gizi yang optimal selama masa 1000 hari pertumbuhan, diperlukan upaya perbaikan gizi sejak ibu hamil, bayi, dan balita, sehingga melahirkan anak yang sehat. Bagaimana menjamin ibu hamil bisa melalui periode emas tersebut dengan baik hingga merawat bayinya sampai 2 tahun.

Fakta-fakta ilmiah sudah sangat jelas diuraikan bahwa kelalaian atau kelengahan memperbaiki gizi pada awal kehidupan, yakni pemenuhan asupan gizi (makro dan mikro) secara seimbang, yang diperoleh dari saat tumbuh dalam rahim ibunya, menyusui (ASI) eksklusif sampai 6 bulan, dan diteruskan dengan ASI dan makanan peralihan ASI (MP-ASI), akan menentukan masa depan anak di kemudian hari.
Pertumbuhan bayi yang sehat akan menjadikannya anak yang sehat dan produktif, dan terus berkembang menjadi orang dewasa yang mampu membangun keluarga yang juga sehat dan produktif. Jika ini terjadi, rantai kemiskinan berhasil diputus, dan diharapkan keluarga yang sehat akan tumbuh.

Pelayanan asuhan antenatal merupakan cara penting memonitor dan mendukung kesehatan dan mendeteksi kehamilan ibu. Ibu hamil sebaiknya dianjurkan mengunjungi bidan atau dokter sedini mungkin semenjak ibu merasa dirinya hamil untuk mendapatkan pelayanan atau asuhan antenatal. Pemeriksaan dan pengawasan terhadap ibu hamil sangat perlu dilakukan secara teratur. Hal ini bertujuan untuk menyiapkan seoptimal mungkin fisik dan mental ibu dan anak selama dalam kehamilan, persalinan dan nifas sehingga didapatkan ibu dan anak yang sehat dan berkualitas.

\section{KESIMPULAN}

Ada pengaruh edukasi pada ibu hamil terhadap peningkatan pengetahuan tentang 1000 hari pertama kehidupan.

\section{SARAN}

Edukasi ini diharapkan dapat meningkatkan niat ibu dan pada akhirnya menjadi perilaku pada ibu hamil dan keluarga terhadap pemenuhan gizi pada 1000 HPK.

\section{REFERENSI}

Badan Perencanaan Pembangunan Nasional (BAPPENAS). 2010. Laporan Pencapaian Tujuan Pembangunan Milenium di Indonesia 2010. In. Jakarta: Kementerian Perencanaan Pembangunan Nasional; 2010.

Dian Nurlaela. (2018). Efektivitas Pendidikan Kesehatan Melalui Media Kartu Cinta Anak Tentang 1000 Hari Pertama Kehidupan dalam Meningkatkan Pengetahuan Pasangan Calon Pengantin di KUA Kecamatan Jatinangor. Jurnal Kesehatan Vokasional Unversitas Padjajaran Bandung, Vol 3, No 2. (2018).

Kemenkes RI. 2014. 1000 hari pertumbuhan yang menentukan. In. Jakarta: Kementerian Kesehatan Republik Indonesia; 2014. 
UNICEF Indonesia. Ringkasan Kajian Kesehatan Ibu dan Anak. Available at: URL: www.unicef.org. Accessed Agustus 17, 2019.

Litbangkes RI. Laporan Riset Kesehatan Dasar. In. Jakarta: Kementerian Kesehatan RI; 2018.

Litbangkes RI. Laporan Riset Kesehatan Dasar. In. Jakarta: Kementerian Kesehatan RI; 2017.

Mutiara Ramadhan. (2017). Hubungan Pengetahuan 1000 Hari Pertama Kehidupan dan Dukungan Keluarga dengan Kepatuhan ibu Hamil dalam Mengonsumsi Tablet Fe. Jurnal Fakultas Kesehatan Masyarakat Universitas Airlangga Surabaya (2017).

Notoatmodjo, S. (2016). Metodologi Penelitian Kesehatan. Jakarta: Rineka Cipta.

Notoatmodjo, S. (2016). Promosi Kesehatan dan IImu Perilaku. Jakarta: Rineka Cipta.

Rosani Naim, dkk. (2017). Pengaruh Edukasi Berbasis Keluarga terhadap Intensi Ibu Hamil untuk Optimalisasi Nutrisi pada 1000 Hari
Pertama Kehidupan. Jurnal Keperawatan Padjajaran Bandung, Vol 5, No 2 (181-196) (2017).

Shofiyyatunnisaak. (2016). Hubungan

Perilaku ibu tentang 1000 Hari

Pertama Kehidpan dengan Status

Gizi Baduta di Wilayah Pedesaan. Jurnal Nutrition Science IPB University Bogor Indonesia (2016).

The 1000 Days Partnership. Why 1000 days. Available at: URL: http://www.thousanddays.org. Accessed July 15, 2019.

World Health Organization. Analisis Lanskap Kajian Negara Indonesia. Available at: URL: www.who.int. Accessed Agustus 20, 2019.

Wawan A, Dewi M.. (2015). Teori dan Pengukuran Pengetahuan, Sikap dan Perilaku Manusia. Jakarta: Nuha Medika

Woods L. Seven key reasons why the first 1000 days are critical. Available at: URL: http://www.everychildcounts.or g.nz/resources/seven-reasons/. Accessed July 15, 2019. 
Tabel 1. Karakteristik responden tentang pentingnya 1000 hari pertama kehidupan terhadap pengetahuan ibu hamil di wilayah kerja Puskesmas Tamalate Kota Makassar

\begin{tabular}{lcc}
\hline \multicolumn{1}{c}{ Variabel } & Jumlah $(\mathrm{n})$ & Persentase $(\%)$ \\
\hline Umur (thn) & 4 & \\
$<20$ & 66 & 4,5 \\
$20-35$ & 19 & 74,2 \\
$>35$ & & 21,3 \\
\hline Umur Kehamilan & 27 & 30,3 \\
Trimester 1 & 31 & 34,8 \\
Trimester 2 & 31 & 34,8 \\
Trimester 3 & & \\
\hline Pendidikan & 19 & 21,3 \\
SMP & 68 & 76,4 \\
SMA & 2 & 2,2 \\
PT & & \\
Pekerjaan & 39 & 43,8 \\
Bekerja & 50 & 56,2 \\
Tidak bekerja & &
\end{tabular}

Sumber : Data Primer tahun 2020

Tabel 2. Hasil pretest responden tentang pentingnya 1000 hari pertama kehidupan terhadap pengetahuan ibu hamil di wilayah kerja Puskesmas Tamalate Kota Makassar

\begin{tabular}{ccc}
\hline Jawaban Pretest & $\mathbf{n}=\mathbf{8 9}$ & Persentase (\%) \\
\hline Pengetahuan baik & 39 & 43,8 \\
Pengetahuan kurang & 50 & 56,2 \\
\hline Sumber data primer tahun 2020 & &
\end{tabular}

Tabel 3. Hasil posttest responden tentang pentingnya 1000 hari pertama kehidupan terhadap pengetahuan ibu hamil di wilayah kerja Puskesmas Tamalate Kota Makassar

\begin{tabular}{ccc}
\hline Jawaban Posttest & $\mathbf{n = 8 9}$ & Persentase (\%) \\
\hline & & 94,4 \\
Pengetahuan baik & 5 & 5,6 \\
Pengetahuan kurang & &
\end{tabular}


Tabel 4. Hasil analisis peningkatan pengetahuan ibu hamil tentang 1000 Hari Pertama Kehidupan

\begin{tabular}{llcccc}
\hline & & \multicolumn{2}{c}{ Posttest } & Total & Nilai p \\
\cline { 3 - 6 } & $\begin{array}{l}\text { Pengetahuan } \\
\text { baik }\end{array}$ & $\begin{array}{l}\text { Pengetahuan } \\
\text { kurang }\end{array}$ & & \\
\hline Pretest & $\begin{array}{l}\text { Pengetahuan } \\
\text { baik }\end{array}$ & $39(43,8)$ & $0(0,0)$ & $39(43,8)$ & 0,000 \\
\hline $\begin{array}{l}\text { Pengetahuan } \\
\text { kurang }\end{array}$ & $45(50,6)$ & $5(5,6)$ & $50(56,2)$ & \\
\hline & $84(94,4)$ & $5(5,6)$ & $\begin{array}{c}89 \\
(100,0)\end{array}$ & \\
\hline
\end{tabular}

Uji McNemar 